LICENÇA CC BY:

Artigo distribuído sob os termos

Creative Commons, permite uso e distribuição irrestrita em qualquer meio desde que o autor credite a fonte original.

\section{SOBRE AS PRÁTICAS “INVISÍVEIS” DA DOCÊNCIA: OLHARES A PARTIR DE PRESSUPOSTOS DA HISTÓRIA CULTURAL}

ABOUT "INVISIBLE" PRACTICES OF TEACHING: LOOKS FROM THE PRESUPPOSITIONS OF CULTURAL HISTORY

SOBRE LAS PRÁCTICAS "INVISIBLES" DE LA DOCENCIA: MIRADAS A PARTIR DE PRESUPUESTOS DE LA HISTORIA CULTURAL

Nathália Cristina Amorim Tamaio de Souza ${ }^{1}$

${ }^{1}$ Doutoranda em Educação pela Universidade Estadual de Campinas (UNICAMP), Campinas, SP, Brasil.

Resumo: Neste ensaio é realizada uma discussão em torno das práticas "invisíveis" da docência. Trata-se de um estudo de natureza teórica, construído a partir de inquietações da autora sobre a sutileza das práticas cotidianas assumidas pelos professores face a situações de controle às quais são submetidos constantemente. A abordagem conceitual reside nos pressupostos da História Cultural, mais especificamente nas contribuições de Michel de Certeau, Michelle Perrot, Anne-Marie Chartier e Carlo Ginzburg, para fundamentar as proposições suscitadas. Como principal apontamento, ressalta-se que mesmo a docência sendo exercida em meio a subordinações, o professor sempre lançará mão de apropriações, desvios e reempregos ao realizar ações pautadas em seus modos próprios de fazer. Presume-se que é para essas ações, geralmente negligenciadas, que precisamos voltar nossos olhares para entendermos as sinuosidades presentes no fazer docente.

Palavras-chave: Docência; Práticas cotidianas; História Cultural.

Abstract: In this essay there is a discussion about the "invisible" aspects of teaching. It is a theoretical study, built on the author's concerns about the subtlety of the daily practices assumed by teachers in relation to the control situations to which they are constantly subjected. The conceptual approach resides in the assumptions of Cultural History, more specifically in the contributions of Michel de Certeau, Michelle Perrot, Anne-Marie Chartier and Carlo Ginzburg, to substantiate the propositions raised. As a main point, it is emphasized that even teaching being exercised in the midst of subordination, the teacher will always use appropriations, deviations and reemployment when performing actions based on their own modes of doing. It is presumed that it's for these actions, generally neglected, that we must turn our observation to understand the sinuosities present in the teaching.

Keywords: Teaching; Quotidian practices; Cultural History.

Resumen: En este ensayo se realiza una discusión en torno a las prácticas "invisibles" de la docencia. Se trata de un estudio de naturaleza teórica, construido a partir de inquietudes de la autora sobre la sutileza de las prácticas cotidianas asumidas por los profesores frente a las situaciones de control a las que son sometidos constantemente. 
El enfoque conceptual reside en los supuestos de la Historia Cultural, más específicamente en las contribuciones de Michel de Certeau, Michelle Perrot, Anne-Marie Chartier y Carlo Ginzburg, para fundamentar las proposiciones suscitadas. Como principal apunte, se resalta que incluso la docencia siendo ejercida en medio de subordinaciones, el profesor siempre lanzará mano de apropiaciones, desvíos y reemplementos al realizar acciones pautadas en sus modos propios de hacer. Se supone que es para esas acciones, generalmente descuidadas, que necesitamos volver nuestras miradas para entender las sinuosidades presentes en el hacer docente.

Palabras clave: Docencia; Prácticas cotidianas; Historia Cultural.

O cotidiano é aquilo que nos é dado cada dia (ou que nos cabe em partilha), nos pressiona dia após dia, nos oprime, pois existe uma opressão no presente. [...] 0 cotidiano é aquilo que nos prende intimamente, a partir do interior. [...] É uma história a caminho de nós mesmos, quase em retirada, às vezes velada. [...] 0 que interessa ao historiador do cotidiano é o Invisível. (CERTEAU, 1996, p. 31).

\section{Contextualizando a problemática}

Desde o início de minha trajetória acadêmica venho me dedicando aos estudos que tomam a docência e suas especificidades como objeto de investigação, seja ela em seu período de constituição inicial, ou em seu auge de desenvolvimento profissional. Para mim, sempre pareceu muito instigante a busca por conhecimentos que expliquem a transição da condição de sujeitoestudante para sujeitoprofessor, bem como todas as implicações desse processo, principalmente no que concerne à construção da arte de ensinar em situações nem sempre favoráveis.

Parte do meu empenho em estudar esse tema com insistência é, seguramente, proveniente da importância que atribuo às práticas mais sutis manifestadas pelos professores na condução de suas tarefas cotidianas, pois estas raramente ganham relevo nas pesquisas da área, já que a tônica costuma residir nos aspectos observáveis com mais nitidez, como as técnicas e metodologias de ensino, as condições concretas de trabalho da categoria, o uso adequado de materiais e recursos pedagógicos etc. Pouco se fala sobre as relações e os usos que o professor, enquanto sujeito pensante, faz entre uma orientação que recebe e o desdobramento que pratica em contexto de sala de aula, entre um 'concordo' que pronuncia e um 'concordo parcialmente' ou 'discordo' que pondera, entre a obediência e a subversão, ainda que a última apresente-se de forma quase imperceptível, e sobre a relevância de tais questões na formação docente. Problematizá-las, sobretudo com minha imersão em teorias que não apenas partilham como dão sustentação às inquietações que sempre tive, é o que tem me gerado profundo interesse. 
Pensando nisso e na confluência de ideias de autores pertencentes ao aporte teórico da História Cultural, especialmente Michel de Certeau e sua concepção de invenção das práticas cotidianas, Michelle Perrot e sua refinada percepção sobre as astúcias dos sujeitos comuns, Anne-Marie Chartier e sua desconfiança em relação à homogeneidade das práticas escolares, e Carlo Ginzburg e sua defesa de um paradigma indiciário, inscrevo o presente ensaio a fim de gerar uma reflexão sobre como podemos interpretar as práticas 'invisíveis' - entre aspas porque não são totalmente invisíveis - dos professores face aos mecanismos de autoridade que circundam suas ações em sala de aula.

A sequência argumentativa do texto consiste em apresentar as contribuições dos autores selecionados em seções independentes, a fim de que se possam evidenciar os diferentes olhares trazidos pelo referencial sobre o tema proposto. Olhares esses que, enredados, fornecem pistas à compreensão dos meandros existentes no fazer docente.

\section{Michel de Certeau: um olhar para os aspectos das práticas cotidianas}

Certeau (1985), ao proferir uma fala sobre sua teoria das práticas cotidianas na Conferência intitulada: "Teoria e método no estudo das práticas cotidianas", alega que aproximar-se das práticas é aproximar-se da maneira de se por em prática um lugar, um rito, uma representação, e de procurar compreender quais usos e operações as pessoas fazem daquilo que lhes é conferido. A abordagem de estudos eleita pelo autor, orientada pela investigação das práticas, possibilita decifrar os mecanismos de funcionamento das esferas macro e micro de uma sociedade e a configuração das formas de organização dos sujeitos sociais. Para ele, as práticas possuem um triplo aspecto, caracterizado pelo caráter estético, pelo ético e pelo polêmico.

O caráter estético diz respeito aos modos diversos e individuais de se usar um determinado objeto, uma linguagem, um lugar. Esse modo de uso é qualificado por uma expressividade que está relacionada ao estilo. Mas, a que se refere tal estilo? Para Certeau (1985), o estilo é fundamentalmente a maneira de se utilizar as palavras, de se produzir um discurso a partir de um esquema linguístico que nos é imposto; é o que se cria e se produz a partir do que nos é apresentado ou instituído por outros sujeitos.

O caráter ético centra-se na recusa ao alinhamento à ordem imposta; é uma ação de abrir um espaço que não é fundado sobre a realidade existente; é uma vontade de inventar, de criar algo, isto é, "uma vontade histórica de existir" (Certeau, 1985, p. 8).

O terceiro aspecto, o caráter polêmico, está marcado por uma relação de forças. As práticas cotidianas se inserem como intervenções nas quais o mais fraco se utiliza de forças existentes como maneira de se defender do mais forte. 
Ao considerar os aspectos supracitados, Certeau tece uma analogia entre as práticas cotidianas e a ação do caçador que adentra florestas alheias para caçar ilicitamente, apoiando-se na expressão "caça furtiva".

Penso que a maioria das práticas do cotidiano são práticas de furtividade. Isto quer dizer que em um espaço que não nos pertence - a rua, o edifício, o lugar de trabalho - agimos sorrateiramente, tentamos tirar vantagem, por meio de práticas muito sutis, muito disfarçadas, de um lugar do qual não somos proprietários (Certeau, 1985, p. 5).

Analisar as práticas cotidianas do ponto de vista da furtividade, como ações que buscam em lugares alheios algo que as constitua, é desmistificar a ideia de um sujeito passivo e receptor, atribuindo-Ihe um papel de agente, de produtor e de autor de um modo específico de se fazer presente no mundo.

O autor trata, portanto, da possibilidade da prática de invenção pelos sujeitos que representam o lado não dominante da sociedade: o sujeito simples, comum ou, de acordo com suas palavras, o sujeito ordinário (CERTEAU, 1994). Sujeitos que inventam e reinventam não por causa do que fazem ou do que dizem, mas porque como "personagens secretos" levam uma vida própria e com suas forças mudas estendem suas ramificações que penetram toda rede da vida cotidiana no teatro dessas relações (CERTEAU, 1996). Por essa ótica, Certeau nos traz certa esperança nas condições reais de o sujeito preservar sua autonomia ou descobrir momentos de escape e indisciplina mesmo quando se encontra em um ambiente repleto de controle e supervisão.

A partir dessas reflexões, pode-se pensar no espaço físico de uma sala de aula como um lugar alheio, um local que não é próprio do professor, que é demarcado para promover ações a partir do que é pré-determinado em termos de organização, de fixação de materiais, e de uma mediação pedagógica orientada por diretrizes já estabelecidas, mas que, ao mesmo tempo, é também o lugar em que o professor exerce a atividade docente empregando suas maneiras próprias de agir, praticando suas invenções, impetradas por táticas ou "artes dos fracos" (VIDAL, s.d, p. 88), apropriando-se tanto desse espaço quanto do conjunto de normas intrínseco a ele, e repelindo o que não condiz com sua realidade.

Um exemplo clássico de invenção docente, designada neste ensaio como práticas 'invisíveis' da docência, refere-se ao uso do material didático. Sabe-se que em muitas escolas são adotados determinados livros ou sistemas apostilados para o norteamento dos conteúdos curriculares. No entanto, sabe-se, também, que significativa parcela dos professores faz uso adaptado desses materiais ou simplesmente recusa-se a utilizá-los, mesmo que nem sempre admitam essa escolha explicitamente. Nesse tipo de conduta, que transparece resistência, mais do que visualizar uma mera oposição, concebe-se a arte de imprimir uma marca, de subverter a ordem para registrar uma existência. 


\section{Michelle Perrot: um olhar para as táticas de subversão}

O breve, porém pontual, texto de Perrot (1998) intitulado "Mil maneiras de caçar" evidencia o diálogo que a autora estabelece com Certeau e os conceitos por ele cunhados para explicar os mecanismos de estratégia e tática. A maneira como a autora se apropria das ideias certeaunianas e cria novas linhas argumentativas, articulando exemplos palpáveis de práticas cotidianas, fez com que seu manuscrito tivesse grande valia às elaborações que venho construindo.

Perrot (1998) nos traz um relato de situações cotidianas ocorridas em uma fábrica para mostrar, entre descrições e comentários, o poder que o sujeito simples, nesse caso específico compreendido como o operário, tem para garantir espaços de subversão no próprio centro de um sistema de supervisão. Para ilustrar essa façanha, são mencionados os momentos em que os operários refugiavam-se nos ditos barracos de zinco para terem momentos de conversa em pleno horário de expediente, e também aqueles reservados para a ducha, quando podiam se reunir e se distrair. Momentos esses desfrutados no mesmo ambiente em que a prática de submissão parecia ser condição permanente e, o rigor, inexorável.

À habilidade de esquiva do sujeito comum - que se refere ao conceito de tática (CERTEAU, 1994) -, em relação ao controle proveniente da classe dominante - compreendido como estratégia (CERTEAU, 1994) -, Perrot (1998) sugere os termos 'artes de dar golpe' ou 'artes da fuga'. Segundo ela, o golpe sempre vem do mais fraco, daquele que, mesmo imerso em contextos cotidianos que lhe impõe determinado comportamento, encontra brechas para agir com seus modos próprios, ainda que involuntariamente. Se transferirmos a lógica do episódio da fábrica, apresentado por Michelle Perrot, ao contexto escolar, será possível verificar que golpes de natureza semelhante são diariamente dados pelos professores em sala de aula. Uma ilustração disso é a própria organização curricular, consubstanciada por documentos e orientações para o desenvolvimento do trabalho docente. Embora o currículo disponha de instruções específicas sobre 'o que ensinar' e 'como ensinar' no exercício cotidiano da docência, o professor inevitavelmente lançará mão de diferentes táticas para compor a aula à sua maneira.

É claro que num primeiro momento o professor se apropriará do conjunto de normas estabelecidas, já que não se funda uma prática profissional em um ambiente de total desordem. No entanto, à medida que as práticas forem se instituindo tomarão novas formas, novos usos e reempregos. Com isso, o que se quer dizer é que para cada arranjo sempre haverá um rearranjo, pois as práticas cotidianas não são estáticas e tampouco previsíveis.

Para Perrot (1998, p. 60), o movimento do golpe significa que dentro do espaço da ordem existe uma "organização clandestina, um verdadeiro contrapoder que 
permite aos trabalhadores desarticulados a reconstituição de sua identidade" e até mesmo de sua autonomia profissional. A fim de aprofundar esse olhar apresento, na próxima seção, as contribuições de Anne-Marie Chartier.

\section{Anne-Marie Chartier: um olhar para as artes de fazer propriamente escolares}

Eleger Anne-Marie Chartier como referencial da História Cultural para a compreensão da faceta 'invisível' do trabalho docente foi, a meu ver, a escolha mais coerente que eu poderia ter feito. Isso porque, além de a autora produzir um modo de olhar para as práticas inegavelmente inspirado nas asserções de Certeau, ela enfatiza as práticas ocorridas na escola a partir de questões que envolvem alfabetização, leitura e escrita, o percurso histórico da formação de professores, e o cotidiano escolar.

Em entrevista recente para a revista Espaço Pedagógico, Chartier (2016) classifica a influência das obras de Certeau como lufadas de oxigênio em seu trabalho de investigação sobre o espaço de ação da prática docente. Ela relata que o autor:

[...] tratava como um gesto cultural "a invenção do cotidiano", ele obrigava a pensar a "formalidade das práticas" enquanto meus estudos de filosofia me tinham ensinado a refletir sobre o conteúdo das teorias. Eram tantas pistas para observar a escola (e seus atores) de outra maneira. A experiência tornava-se um saber à parte, completo, fonte de "artes do fazer", não necessariamente legitimado no discurso sobre a instituição escolar. [...] Para ele, a cultura era "uma arte de fazer", portanto uma prática. Era exatamente disso que eu necessitava para observar "de outra maneira" o trabalho dos professores da escola primária (CHARTIER, 2016, p. 223).

É bastante precioso o olhar que Anne-Marie constrói para pensar a docência. Um olhar de dentro para fora, que considera as práticas do sujeito como objeto de pesquisa que pode ser explicado pela própria prática mais do que por qualquer outra teoria.

Na obra "Práticas de leitura e escrita: história e atualidade", Chartier (2007) nos leva a pensar que um dos desafios da pesquisa educacional é justamente 'situar a escola real', abrir a 'caixa preta', isto é, expor e compreender como a escola funciona, como os sujeitos que a constroem se apropriam das prescrições do sistema, das heranças da cultura escolar, da diversidade oriunda dos diferentes modos de vida com que cada um participa das relações estabelecidas nesse espaço, já que, segundo seus pressupostos, não há homogeneidade nas práticas escolares. Com relação a isso, a autora afirma que é necessário sair das representações que congelam a escola num estado estável. É preciso procurar ver as dinâmicas que nela operam, que podem ser positivas, tais como a diminuição de evasões escolares e podem também ser nefastas, como a imposição de metas internacionais que não consideram nem culturas nacionais nem públicos de alunos (CHARTIER, 2016). 
No centro desse processo situam-se os professores. Para entender o papel ativo que desempenham em face de toda essa dinâmica é preciso prestar atenção às reações que eles esboçam, ao modo como eles aceitam ou recusam prescrições e quais são os indícios que eles nos dão para detectar essas sutis formas de manifestar suas "artes de fazer" (CERTEAU, 1994).

Carvalho e Hansen (2009), em um texto que descreve a trajetória e obra de AnneMarie, resgatam a visibilidade que a estudiosa dá às práticas enquanto algo que se compõe de microtáticas elementares que convergem no que ela chama de 'fazeres ordinários'. Assim, interpretar tais práticas significa compreendê-las como:

[...] caças furtivas em território alheio ou práticas inventivas que, em campo inimigo, subvertem os dispositivos de poder que, estratégicos, objetivam moldá-las, cerceá-las, impedi-las; dispositivos de poder que são também a condição de possibilidade, o solo, a circunstância e a matéria dessas artes de fazer com que são os fazeres ordinários da classe (CARVALHO; HANSEN, 2009, p. 39).

Diante dessas formulações, faz-se oportuno mencionar o que Anne-Marie pondera sobre o foco que as pesquisas em educação têm tomado, sobretudo na América Latina. Para ela, a insistência em se estudar as políticas educacionais para explicar os problemas do ensino é, no mínimo, paradoxal. Se os problemas emergem nas práticas do cotidiano das escolas, nas tensões criadas pelas relações entre diferentes sujeitos e na forma com que esses sujeitos lidam com os objetos do conhecimento, é para estas práticas que precisamos olhar. Precisamos, sobretudo, olhar para o que poucos pesquisadores reparam e que, portanto, é facilmente negligenciado. Sobre isso, Ginzburg nos esclarecerá a seguir.

\section{Carlo Ginzburg: um olhar para o não evidente}

Conforme Ginzburg (1989), por milênios o homem foi caçador. Aprendeu, então, a farejar, registrar, interpretar e classificar pistas, a detectar os mais ínfimos sinais. É a partir desse tipo de conhecimento, com raízes muito antigas, valendo-se da própria evolução da humanidade, que Ginzburg anuncia o paradigma indiciário, compreendido como formas de saber tendencialmente mudas - no sentido de que suas regras não se prestam a ser formalizadas nem ditas (GINZBURG, 1989, p. 179).

Contemplando o conjunto de operações definidoras do paradigma indiciário e pautado na tripla analogia que estabelece com os exemplos de Morelli, Sherlock Holmes e Freud, Ginzburg (1989) recompõe o complexo de atributos que caracterizam sua distintiva natureza, atribuindo-lhe identidade metodológica, marcada pela qualificação da natureza do indício (pistas, traços).

Destarte, o modelo indiciário emerge, trazendo uma importante contribuição ao passo que desvela o não dito, o não revelado claramente, com os contrassensos, pausas, silêncios, distrações, negações e repetições e com o relato de histórias de 
vida, buscando no passado explicações para o presente e, possivelmente, elementos para tencionar o futuro. Pelo modelo em questão, é possível buscar o entendimento de atitudes, mudanças e mecanismos criados pelos sujeitos como forma de mediação com a realidade. $\mathrm{E}$, "se a realidade é opaca, existem zonas privilegiadas - sinais, indícios - que permitem decifrá-la. [...] Essa ideia constitui o ponto essencial do paradigma indiciário". (GINZBURG, 1989, p. 177).

Nessa perspectiva, Ginzburg (1989) destaca que "[...] é preciso não se basear, como normalmente se faz, em características mais vistosas, portanto mais facilmente imitáveis [...]. Pelo contrário, é necessário examinar os pormenores mais negligenciáveis" (p. 144) que permitam desvendar "uma realidade mais profunda, de outra forma inatingível". (p. 150). Em linhas gerais, o autor defende um modelo cognoscitivo de se interpretar algo através de um sinal, um ato falho, um desvio.

Por essa via de raciocínio, os pressupostos levantados por Ginzburg mostramse fecundos para as discussões que vêm sendo tecidas neste texto na medida em que fornecem pistas para o entendimento dos aspectos que geralmente passam despercebidos nas situações sorrateiras do cotidiano.

É bastante provável que em algum momento de nossas vidas tenhamos nos deparado com situações em que, por mais esforços que tenham sido empreendidos, não conseguimos decifrar problemas aparentemente óbvios. Isso acontece porque, conforme explica Ginzburg, tendemos a nos apegar aos aspectos mais evidentes e, portanto, superficiais, desses problemas. Na visão do autor, o deslocamento do foco de atenção para aquilo que não é evidente seria o caminho mais fértil para o encontro de respostas aprofundadas, para uma compreensão mais apurada da realidade vivida ou observada.

Em educação e, mais precisamente, na esfera da docência, podemos visualizar a possibilidade de desdobramento do paradigma indiciário por intermédio de estudos que encontram morada nas práticas, visto que nelas contêm uma série de desvios que nem sempre são aparentes, como os mencionados nas seções anteriores, quando das discussões à luz de Certeau, Perrot e Chartier. No entanto, cumpre alertar que analisar as práticas, um processo que se dá tanto pelo discurso quanto pelo silêncio, é uma tarefa de alta complexidade que demanda um olhar cauteloso por parte do pesquisador, pois, ainda que se verifique um desvio passível de análise, há de se ter em mente que interpretar fielmente a história do outro é uma ingenuidade, já que, assim como os textos, as práticas têm "fendas" (GINZBURG, 2002, p. 99).

\section{Considerações finais}

Chegar ao momento das considerações finais me faz pensar na problemática que suscitou o início de uma escrita que, aos poucos, foi se abastecendo de ideias. Essa 
problemática, referente ao interesse em entender as práticas invisíveis da docência, contemplou o estudo de quatro autores do campo da História Cultural e suas impressões no que tange ao tema.

Os autores estudados, nos quais busquei apoio para sustentar minhas suposições, foram selecionados e apresentados estrategicamente para que as emendas entre um e outro não demonstrassem fragmentação. Após leituras exaustivas, fui percebendo o ponto de intersecção entre eles e esse exercício facilitou substancialmente a construção do texto.

Assim, tomando o olhar de Certeau como ponto de partida e o de Ginzburg como ponto de chegada, destaco o poder das operações que o professor utiliza para inventar suas próprias maneiras de fazer em uma instituição que, historicamente, é marcada pelo controle. Invenções essas decorrentes de apropriações, seguidas de desvios e de reempregos. Por apropriações, entende-se o ato inicial de acolhimento de determinadas normas, prescrições e orientações que são dadas ou impostas ao sujeito no cotidiano. Os desvios, por sua vez, seriam uma espécie de descarte ou adaptação, uma seleção daquilo que convém ou que é oportuno ao sujeito e a rejeição daquilo que não é. Os reempregos correspondem à ideia de transformação de algo que já foi acolhido e adaptado ou selecionado em um novo formato.

Perante o reconhecimento desse movimento e da importância conferida às suas particularidades para o entendimento das minúcias da docência, é enfatizada a urgência de se considerar o estudo das práticas, pois teoria alguma seria capaz de decifrá-las tão bem quanto elas mesmas, seus pormenores, seus indícios e seus detalhes, como diria Anne-Marie Chartier.

Mas, cabe observar que decifrar as práticas sutis ou 'invisíveis', ainda que seja o caminho mais fecundo para o levantamento de dados aprofundados, é também um trabalho que requer parcimônia quanto à interpretação feita pelo pesquisador, já que nem sempre aquilo que depreendemos abrange fidedignamente o que os sujeitos expressam em suas práticas. Nessa lógica, questionava-me ao arquitetar este texto: "Até que ponto poderei interpretar a invisibilidade das práticas docentes?" Agora, chegando ao seu desfecho, respondo-me: "Até o ponto em que a minha interpretação não tenha a ingenuidade de colocá-las no campo do completamente visível". Escolho, então, aceitar as fendas.

\section{Referências}

CERTEAU, M. A invenção do cotidiano: artes de fazer. Petrópolis/RJ: Vozes, 1994.

CERTEAU, M. A invenção do cotidiano 2: morar, cozinhar. Petrópolis/RJ: Vozes, 1996.

CERTEAU, M. Teoria e Método no Estudo das Práticas Cotidianas. In: SZMRECSANY, M. I. (org.) 
Cotidiano, cultura popular e planejamento urbano. (Anais do encontro). São Paulo: FAU/ USP, 1985.

CARVALHO, M. C.; HANSEN, J. A. Anne-Marie Chartier: historiadora das práticas culturais. In: Revista Pedagogia Contemporânea. São Paulo: Ed Segmento, vol. 3, pp. 28-43, 2009.

CHARTIER, A-M. Diálogo com Anne-Marie Chartier. In: Revista Espaço Pedagógico. Passo Fundo, vol. 23, n. 1, pp. 221-229, 2016.

CHARTIER, A-M. Práticas de leitura e escrita: história e atualidade. Belo Horizonte: Ceale/ Autêntica, 2007.

GINZBURG, C. As vozes do outro: uma revolta indígena nas ilhas marianas. In: GINZBURG, C. Relações de força: história, retórica, prova. São Paulo: Companhia das Letras, 2002.

GINZBURG, C. Sinais: raízes de um paradigma indiciário. In: GINZBURG, C. Mitos, emblemas, sinais: morfologia e história. Companhia das Letras, 1989.

PERROT, M. Mil maneiras de caçar. In: Projeto História. n. 17. São Paulo: EDUC, 1998.

VIDAL, D. G. Michel de Certeau: Historiador-vagabundo, jesuíta errante. In: Revista Pedagogia Contemporânea. São Paulo: Ed Segmento, pp. 76-91, [s.d.].

Artigo recebido em: 14/12/2018 Aprovado em: 04/04/2019

Contato para correspondência: Nathália Cristina Amorim Tamaio de Souza. E-mail: nathytamaio@hotmail.com 